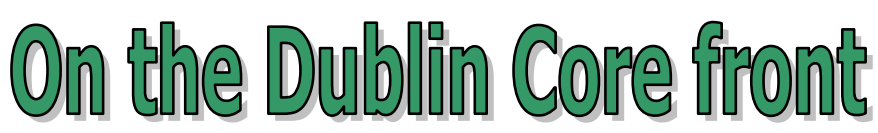

by Norm Medeiros

Associate Librarian of the College

Haverford College

Haverford, PA

\title{
Harvard, NIH, and the Balance of Power in the Open Access Debate
}

\{A published version of this article appears in the 24:3(2008) issue of OCLC Systems E Services.\}

\begin{abstract}
This article reviews the recent decision by Harvard's Faculty of Arts \& Sciences to submit scholarly articles to the University's institutional repository prior to (or in lieu of) publication in a journal. The remarkable decision, the first of its kind in the United States, reverberated quickly across the open access landscape, making many wonder which universities will follow Harvard's lead. This article also looks at the National Institutes of Health (NIH) Public Access Policy, which as of 8 April 2008, requires NIH-sponsored investigators to place into PubMed a copy of their peer-reviewed journal articles. The impact of this legislation will be enormous, as some 80,000 articles per year result from NIH-sponsored research.
\end{abstract}

\section{KEYWORDS}

open access ; Harvard University ; institutional repository; National Institutes of Health ; NIH ; public access

"It's a mere moment in a man's life between the all-star game and the old-timer's game." - Vin Scully

I can't recall who first posited the idea that electronic journals would eliminate the concept of the journal issue, but it's come to pass. In the print world, distribution of a selection of articles packaged in a convenient container was practical. Yet in a world where articles appear without much to remind us of their brethren or provenance, it's not surprising that the concept of the journal issue is all but dead. This isn't a bad thing, just an observation really, but it shows true every time I work with an undergraduate whose research yields either electronic journal articles, or a link to an interlibrary loan form. Never, it seems, is a bound journal needed, further destroying the idea of the issue. The same is happening in music. Album sales continue to decline, to the tune of 25\% since 2000. ${ }^{1}$ Meanwhile ear buds have become a fashion accessory as legal (and illegal) digital singles download at breakneck speed into the ubiquitous iPod. Two recent events will further contribute to this article-as-sovereignobject transformation.

\section{OPEN ACCESS AT HARVARD}

In February, Harvard's Faculty of Arts and Sciences (FAS) voted to grant the university nonexclusive rights to preserve and make accessible its scholarly journal articles. The landmark decision ensures that most articles authored by Harvard FAS will be made freely-available in the University's 
institutional repository (a waiver to opt out of the arrangement is available, which one hopes will be used sparingly). The implications of this remarkable move are numerous, not the least of which being the potential effect on the journal supply chain. The FAS decision is a big win for the managers of the institutional repository. Unlike most repository managers who plead with faculty to submit publications, Harvard's IR staff has the benefit of a faculty that recognizes the good in making freelyavailable its scholarship. The move reminded me of a similar faculty-endorsed motion that occurred in 2003. At that time, the Cornell University Library sought support from the faculty when attempting to break from its "big deal" with Elsevier. The faculty senate endorsed the Library's decision to divest itself of its existing relationship with Elsevier, on the grounds the license to the bundled journals was excessively expensive. Subsequently, several hundred journals were cancelled. The resolution passed by Cornell's faculty in 2003 included the following prophetic passage:

Recognizing that the increasing control by large commercial publishers over the publication and distribution of the faculty's scholarship and research threatens to undermine core academic values promoting broad and rapid dissemination of new knowledge and unrestricted access to the results of scholarship and research, the University Faculty Senate encourages the library and the faculty vigorously to explore and support alternatives to commercial venues for scholarly communication. ${ }^{3}$

Harvard's recent decision brings to fruition this idea. Which universities will follow?

\section{Harvard Open Access Motion}

Harvard University is committed to disseminating the fruits of its research and scholarship as widely as possible. In keeping with that commitment, the Faculty adopts the following policy: Each Faculty member grants to the President and Fellows of Harvard College permission to make available his or her scholarly articles and to exercise the copyright in those articles. In legal terms, the permission granted by each Faculty member is a nonexclusive, irrevocable, paid-up, worldwide license to exercise any and all rights under copyright relating to each of his or her scholarly articles, in any medium, and to authorize others to do the same, provided that the articles are not sold for a profit. The policy will apply to all scholarly articles written while the person is a member of the Faculty except for any articles completed before the adoption of this policy and any articles for which the Faculty member entered into an incompatible licensing or assignment agreement before the adoption of this policy. The Dean or the Dean's designate will waive application of the policy for a particular article upon written request by a Faculty member explaining the need.

To assist the University in distributing the articles, each Faculty member will provide an electronic copy of the final version of the article at no charge to the appropriate representative of the Provost's Office in an appropriate format (such as PDF) specified by the Provost's Office. The Provost's Office may make the article available to the public in an open-access repository.

The Office of the Dean will be responsible for interpreting this policy, resolving disputes concerning its interpretation and application, and recommending changes to the Faculty from time to time. The policy will be reviewed after three years and a report presented to the Faculty. ${ }^{2}$

\section{NIH PUBLIC ACCESS POLICY}

More far-reaching open access news occurred with the passing of the National Institutes of Health (NIH) Public Access Policy (Public Law 110-161, Division G, Title II, Section 218), a part of the Consolidated Appropriations Act of 2008, which mandates the submission into PubMed of peerreviewed journal articles that result from NIH-funded research. The policy, which went into effect 
on 7 April 2008, will provide public access to the roughly 80,000 articles published annually by NIHsponsored investigators. ${ }^{4}$ The law states:

The Director of the National Institutes of Health shall require that all investigators funded by the NIH submit or have submitted for them to the National Library of Medicine's PubMed Central an electronic version of their final, peer-reviewed manuscripts upon acceptance for publication, to be made publicly available no later than 12 months after the official date of publication: Provided, That the NIH shall implement the public access policy in a manner consistent with copyright law. ${ }^{5}$

An earlier access policy ("Policy on Enhancing Public Access to Archived Publications Resulting from NIH-Funded Research") that went into effect on 2 May 2005 requested, but did not mandate, that NIH-sponsored investigators submit research articles to PubMed Central. A paltry percentage of investigators adhered to the suggestion, thus the more rigorous law recently put in place. ${ }^{6}$ Presumably the new law will have a high compliance rate, and provide opportunities for librarians to assist their faculty colleagues with the submission process. The effect of this open access law on publishers will be interesting to watch over the next several years, though the NIH's 12-month embargo should have a minimal effect on subscription revenue. "Add-on" revenue generated from the sale of backfiles, however, may be susceptible to losses as the NIH-sponsored articles are released to the open web.

\section{REFERENCES}

1. United States, Bureau of the Census (2006). Statistical Abstract of the United States: 2007, 126 ${ }^{\text {th }}$ ed. (Lanham, MD: Bernan Press).

2. Harvard University, Faculty of Arts and Sciences (2008). "Agenda." Available: http://www.fas.harvard.edu/ secfas/February_2008_Agenda.pdf (Accessed: 7 April 2008).

3. Cornell University Faculty Senate (2003). "Resolution Regarding the University Library's Policies on Serials Acquisitions, with Special Reference to Negotiations with Elsevier." Available: http://www.library.cornell.edu/scholarlycomm/resolution2.htm (Accessed: 16 April 2008).

4. Association of Research Libraries (2008). “NIH Public Access Policy, Guide for Research Universities." Available: http://www.arl.org/sc/implement/nih/guide/ (Accessed: 7 April 2008).

5. National Institutes of Health (2008). "NIH Public Access Policy." Available: http://publicaccess.nih.gov/policy.htm (Accessed: 7 April 2008).

6. Suber, Peter (2006). “NIH Public Access Policy: Frequently Asked Questions.” Available: http://www.earlham.edu/ peters/fos/nihfaq.htm (Accessed: 24 April 2008). 